is less robust and has a much lower limit-about 1,200 c.p.s. - to its usable frequency range than the cathode ray tube. 4, 6 , and 12-way flight units with either cathode ray tubes or galvanometers retain photographic recording, despite the additional labour and complication. Direct recording is being developed, but the increased inertia when using a stylus has reduced the frequency range of the existing four-way galvo-pen recorder to from zero to 70 c.p.s.

The cameras used have been designed for ready observation of faults, and incorporate means for exposing automatically a predetermined length of film, cutting or perforating between records, and record numbering; they give an accurate and convenient time scale and one or more reference lines on the paper parallel to its direction of motion. Daylight and rapid or mechanical reloading are often required for flight work.

Other exhibits included a torque-meter which measures the angular twist of a shaft in terms of the phase displacement between the E.M.F.s of two identical A.C. generators fixed at a known distance apart on the shaft, and a vacuum tube acceleration pick-up in which the two anodes of a double diode valve are elastically mounted and move with respect to the cathode under impressed acceleration.

The lucid account of recent work, given to visitors in papers written by E. Jones, J. Taylor, J. B. B. Owen, Dr. J. R. Richards, and Dr. J. E. Bennett, of the Royal Aircraft Establishment, has been valuable in the preparation of these notes.

\section{RELEASE OF INFORMATION ON ATOMIC ENERGY}

TN Nature of March 22, 1947 (p. 411), a list was pub1 lished of seventy-three reports on atomic energy and related subjects which had been released by the Ministry of Supply from the category of secret documents. This list of 'declassified' reports on atomic energy has now been augmented, and at the same time a change has been made in the method of making them available to the scientific public. Henceforth, copies will be sold by H.M. Stationery Office, P.O. Box 569, Cornwall House, London, S.E.l, to which application. should be made for reports from either list. It will be necessary only to quote the B.D.D.A. number in the present list, but titles should be quoted in the case of the previous list unless the B.D.D.A. number is known. These reports are in the form of enlarged prints taken from micro-films, and the prices below are for these prints; as an alternative, films could be supplied if desired. The copyright of all such documents is vested in the Crown, and copies nay not be made, nor extracts published, without permission from H.M. Stationery Office.

It is hoped that H.M. Stationery Office will also be in a position shortly to supply documents of American origin on atomic energy, and applications for these should be made to the address given above.

These arrangements do not affect the method by which Canadian documents are obtained from the Plans and Publications Section of the National Research Council, Ottawa (seo Nature, 159, 719 ; 1947).

The British documents newly declassified are as follows :

$\begin{array}{cc}\text { B.D.D.A. } & \text { Report } \\ \text { No. } & \text { No. } \\ 74 & \text { Br. } 195\end{array}$

Title and Author(s) Report on experimental work on fluorine pro-
duction to May, 1939 . Thomson, J. W.

75

76

Br. 50

Investigations on oxides
of $\mathrm{X}^{*}$. Haworth, W. N.

Br. 257

Br. 37

A new method of investigating the angular distribution of high-energy neutrons scattered by
protons. Feather, $N$.

protons. Feather, N. The ipreparation of fluo
ine. Ferguson, J.

Br. 72

Capture cross-sections of

$\mathrm{N}, \mathrm{Mg}, \mathrm{S}$, Ca and $\mathrm{Pb}$ for thermal neutrons. F'enning, F. W., Seligman,

Br. 89

H.

Note on the inelastic scattering of fast neu-

Br. 310

\title{
Neutro
}

Neutron-produced radioactivity in relation to the detection of highmum sensitivity of a muxa sensitivity of

81

82

BI. 68

(Revised

of MS.P.2)

Equilibrium time in a
separation plant. Peierls, sep.

Date Price

June 8, 108. $8 d$. 1939

Nov. 1s. $4 d$. 1943

arch 27, 48. $0 d$.

1942

May 22

1942

108. $8 d$.

1942

28. 0 d.

Effect of a stationary

layer of thickness $b$ in front of the diffusing membrane. Peierls, $R$.

Nov. $14,38.4 d$. Separating effect of a pass. age through capillary. Peierls, R.

MS. 21 Effect of boundary layer for swept membranes. Fuchs, $\mathrm{K}$.

MS. 39 Clusius-Dickel device as gland. Peierls, $\mathbf{R}$.

2A Critical conditions in neutron multiplication. Pryce, M. H. L.

Effect of a scattering container on the critical radius and time constant. Fuchs, $\mathrm{K}$.

Br. 106 Preparation of metallic $X^{*}$ by electrolysis of the fused sarts. Haworth,

"Metalectric" furnace (with sketch). Tomlinson (Metalectric Co., Ltd.). Haworth, W. N. Note on the compression at the diffuser entry in compressor I.Z.I. Fried-
lander, F. G.

trons in trons in hydrogenous media near the source. Booker, D. V., Broda, E., Kowarski, I.

Receiving time and count. ing errors in discriminators and scaling units. Cranshaw, T. E.

Distribution of slow neutrons in rarefled hydrogenous media. Kowarski, L., West, I.

The determination of $\mathrm{X}^{*}$ in urine. A proposed modiflcation and some notes on the method. Jones, A. G.

A new method of determining the time constant of a sphere in a container. Wilson, A. H.

Extraction of protactinium from a silicaceous raw material. Hroda, E.,

Separation of isotopes. Feb. 25, 10s. 0d. Peierls, R., Fuchs, K.

The spectrographic analysis of uranium. 